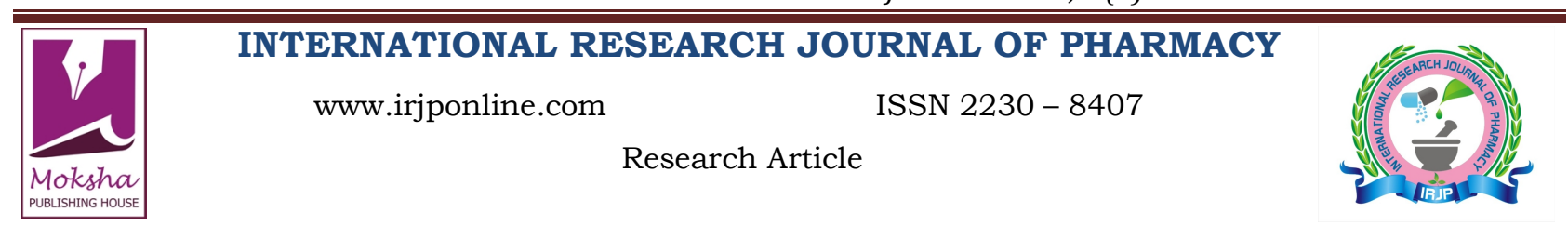

\title{
MICROWAVE ASSISTED GREEN SYNTHESIS OF SILVER NANOPARTICLES USING BOSWELLIA SERRATA FLOWER EXTRACT AND EVALUATION OF THEIR ANTIMICROBIAL ACTIVITY \\ Karunakar Rao Kudle ${ }^{1}$, Manisha R. Donda ${ }^{1}$, Ramchander Merugu ${ }^{1}$, Madhukar Rao Kudle ${ }^{2}$, M.P. Pratap Rudra ${ }^{1 *}$ \\ ${ }^{1}$ Department of Biochemistry, Osmania University, Hyderabad, India \\ ${ }^{2}$ Department of Biochemistry, Kakatiya University, Warangal, India \\ *Corresponding Author Email: mpprataprudra@gmail.com
}

Article Received on: 20/03/13 Revised on: 09/04/13 Approved for publication: 10/05/13

DOI: $10.7897 / 2230-8407.04644$

IRJP is an official publication of Moksha Publishing House. Website: www.mokshaph.com

(C) All rights reserved.

\section{ABSTRACT}

In the present investigation, we describe a cost effective green synthesis of silver nanoparticles from the extract of Boswellia serrata flower as reducing agent. The formed silver nanoparticles were characterized using UV-Vis absorption spectroscopy, Fourier Transfer Infra Red and Scanning Electron Microscope (SEM). The functional group responsible for $\mathrm{Ag}^{0}$ reduction was found to be alkanoid compounds from FTIR. The SEM analysis showed the size of nanoparticles to be between $60-84 \mathrm{~nm}$. Antimicrobial activity of the formed nanoparticles exhibited maximum activity against gram negative bacteria than gram positive bacteria. This is for the first report on the use of Boswellia serrata flower for the synthesis of silver nanoparticles.

Keywords: Microwave, Boswellia serrata Flower, Silver nano particles, UV-visible Spectra, FTIR, SEM, Antibacterial activity.

\section{INTRODUCTION}

Biological methods for the green synthesis of nanoparticles are cost effective and eco-friendly compared to physical and chemical methods. The microbial enzymes and phytochemicals with anti oxidant or reducing properties are usually responsible for reduction of metal compounds into their respective nanoparticles. According to previous investigations, the polyol components and the water-soluble heterocyclic components play significant role in the reduction of silver ions. These components also proved to be a effective capping and stabilizing agents for burn and open wounds ${ }^{1,2}$. Bioreduction of silver ions to yield metal nanoparticles using living plants like geranium leaf and neem leaf ${ }^{3,4}$ have been studied. Pal et al. ${ }^{5}$ have reported the antibacterial activity of AgNPs depends on their size. Seed extract of Cuminum cyminum and Stigmaphyllon littorale were used for silver nanoparticles, ${ }^{6,7}$. We here report the synthesis of silver nanoparticles, using the aqueous extract of Boswellia serrata flower for the first time. This flower extract can act both as reducing and stabilizing agent. The extract is from an important medicinal plant, belonging to the family Burseraceae and genus Boswellia, found in Andhrapradesh and Rajasthan. These flowers have a pleasant scent. The results of the present study are discussed in the light of existing literature.

\section{MATERIALS AND METHODS}

The dried flowers of the Boswellia serrata flowers collected from Tirupati, Andhra Pradesh, India. The flowers were rinsed with water thrice followed by deionized water to remove the fine dust materials and then, the flowers were dried under direct sun light for 2 weeks to completely remove the moisture (Figure 1). The dried flowers were pulverized well with mortar and pestle to make a powder. Ten grams of powder sample was mixed into $100 \mathrm{ml}$ of deionized water and the mixture was boiled for $10 \mathrm{~min}$. After cooling, the flower extract was filtered by a Whatman No.1 filter paper. The filtrate was stored at $4{ }^{\circ} \mathrm{C}$ for further study. For the $\mathrm{Ag}$ nanoparticles synthesis, $1.5 \mathrm{ml}$ of Boswellia serrata flower extract was added to $30 \mathrm{ml}$ of $1 \mathrm{mM}$ aqueous AgNO3 solution in a $100 \mathrm{ml}$ Erlenmeyer flask. The flask was then incubated at
Micro Oven at 15 seconds. A control setup was also maintained without flower extract show (Figure 2). The Ag nanoparticle solution thus obtained was purified by repeated centrifugation at $15,000 \mathrm{rpm}$ for $10 \mathrm{~min}$ followed by redispersion of the pellet in de-ionized water. Formation of silver nanoparticles was confirmed by changing colour light pinkish to brown yellow through UV-visible spectrophotometer, at the range of $300-700 \mathrm{~nm}$. After completion of silver nanoparticles synthesis process (Figure 3 ), the particles were recovered by centrifugation at $10,000 \mathrm{rpm}$ for 15 minutes to isolate $\mathrm{Ag}$ nanoparticles free from other bio-organic compounds present in the solution. After centrifugation the obtained particles were washed with water for 4times and kept it in hot air oven for drying at $80^{\circ} \mathrm{C}$. The morphology of the silver nanoparticles was identified by FTIR and Scanning electron microscopy (SEM). EDX analysis was also used for identifying the elemental composition of silver. The crystal structures of the silver nanoparticles were investigated using XRD. FTIR measurements of flower extract reduced $\mathrm{Ag}^{+}$to $\mathrm{Ag}^{\mathrm{O}}$ nanoparticles were carried out on a Perkin-Elmer FTIR Spectrum. Further study of the antimicrobial activity of the synthesized silver nanoparticle was performed by disc diffusion method.

\section{RESULTS AND DISCUSSION}

The colour change in reaction mixture (metal ion solution + flower extract) was recorded through visual observation. The color change showed the presence of silver nanoparticles in the flower extract and it was characterized by UV-Visible spectrophotometer and monitored by taking readings at regular time intervals in a Perkin Elmer UV-Visible spectrophotometer. The strong surface plasmon resonance band positioned at $460 \mathrm{~nm}$ was observed for silver nanoparticles which increased in intensity as a function of time of reaction and it attained maximum $1 \mathrm{~h}$ of incubation. The silver nanoparticle pellets obtained after centrifugation were redispersed in water prior to FTIR analysis centrifuged again at $15,000 \mathrm{rpm}$ for $10 \mathrm{~min}$ to isolate the $\mathrm{Ag}$ nanoparticles from traces of free proteins or other compounds present in the solution (Figure 4). 
Table: 1 Antibacterial activity of the silver nanoparticles synthesized from Boswellia Serrata flower

\begin{tabular}{|c|c|c|c|c|}
\hline \multicolumn{5}{|c|}{$\begin{array}{c}\text { Inhibition zones study of AgNPs synthesized from the Flower Extract of Boswellia Serrata against Gram } \\
\text { Positive and Negative bacterial species }\end{array}$} \\
\hline Name of Micro Organisms & Flower Extract $(5 \mu \mathrm{l})$ & AgNPs $(5 \mu \mathrm{l})$ & AgNPs $(10 \mu \mathrm{l})$ & Ampicilline (5 $\mu \mathrm{l})$ \\
\hline Pseudomonas aeruginosa & 6 & 7 & 11 & 10 \\
\hline Bacillus subtilis & 6 & 8 & 9 & 10 \\
\hline Klebsiella pneumoniae & 5 & 7 & 10 & 10 \\
\hline Staphylococcus aureus & 5 & 7 & 10 & 11 \\
\hline Pseudomonas putida & 5 & 7 & 10 & 10 \\
\hline Escherichia coli & 5 & 6 & 11 & 9 \\
\hline
\end{tabular}

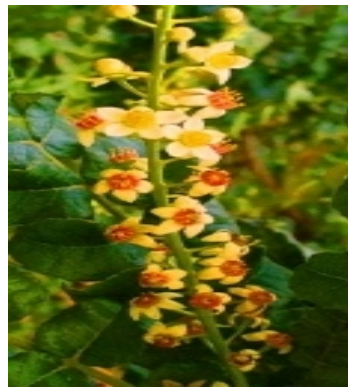

Figure 1: Boswellia Serrata Flower Plants

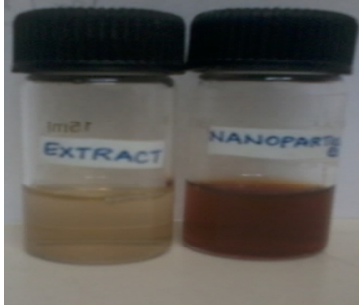

(a)

Figure 2: Test for Boswellia serrata flower (a) Flower Extract (b) to show the synthesis of silver nanoparticles

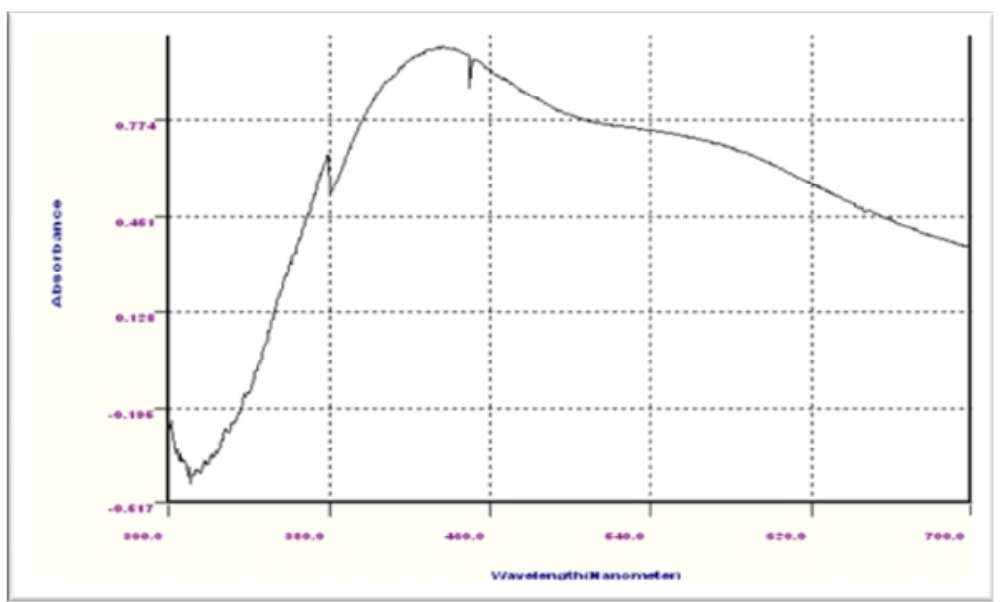

Figure 3: UV-Visible spectrum of silver nanoparticles synthesized by Boswellia serrata flower extract

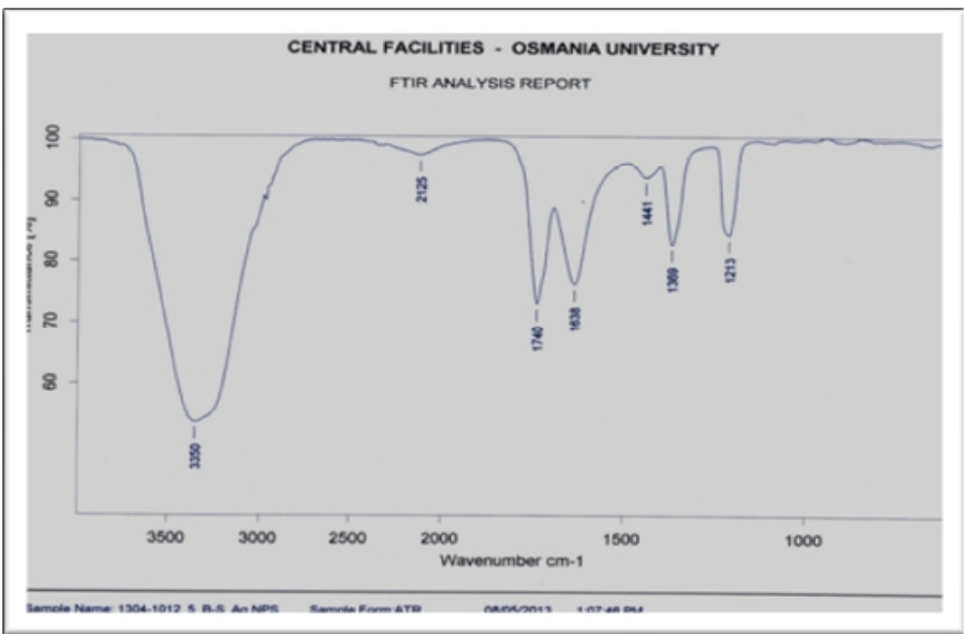

Figure 4: FTIR spectrum of silver nanoparticles synthesized using Boswellia serrata flower extract 


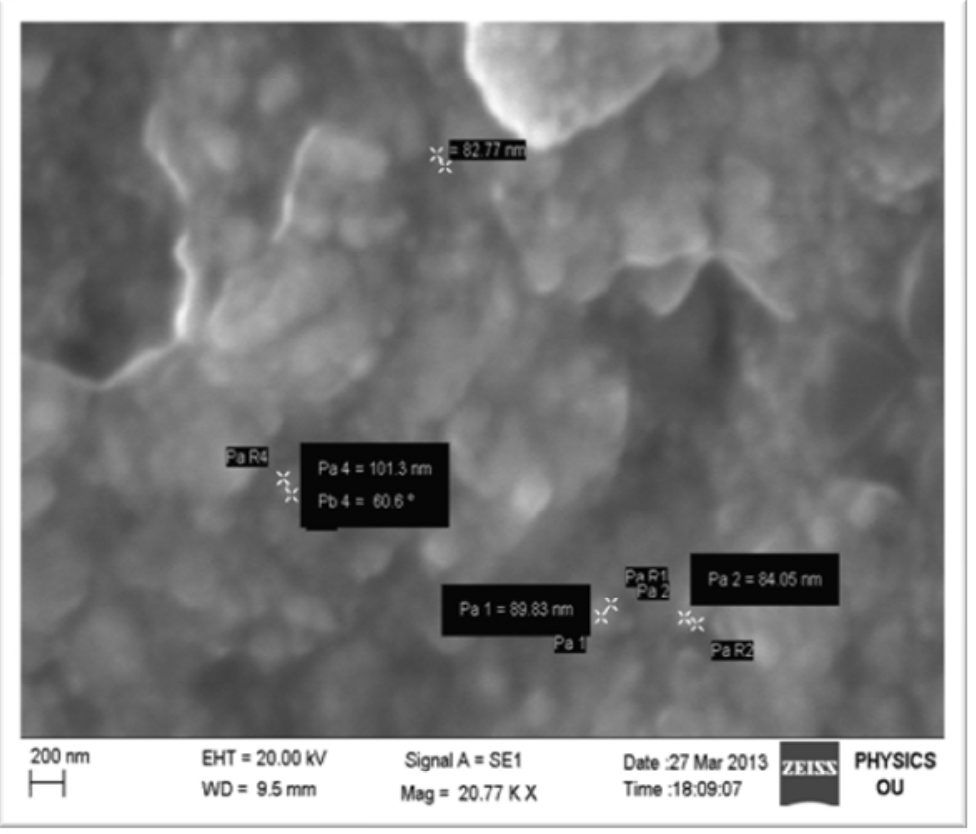

Figure 5: SEM images of silver nanoparticles synthesized from Boswellia serrata flower

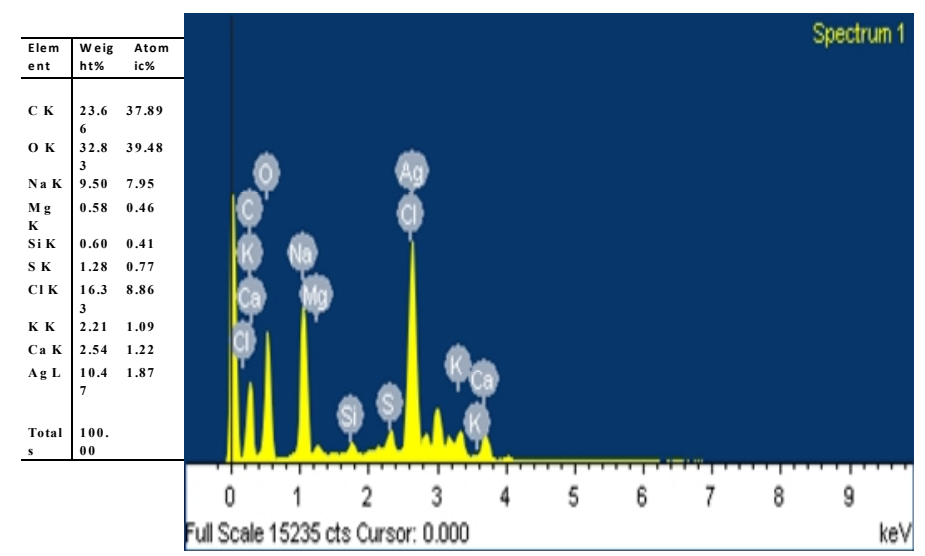

Figure 6: Shows EDX Analysis

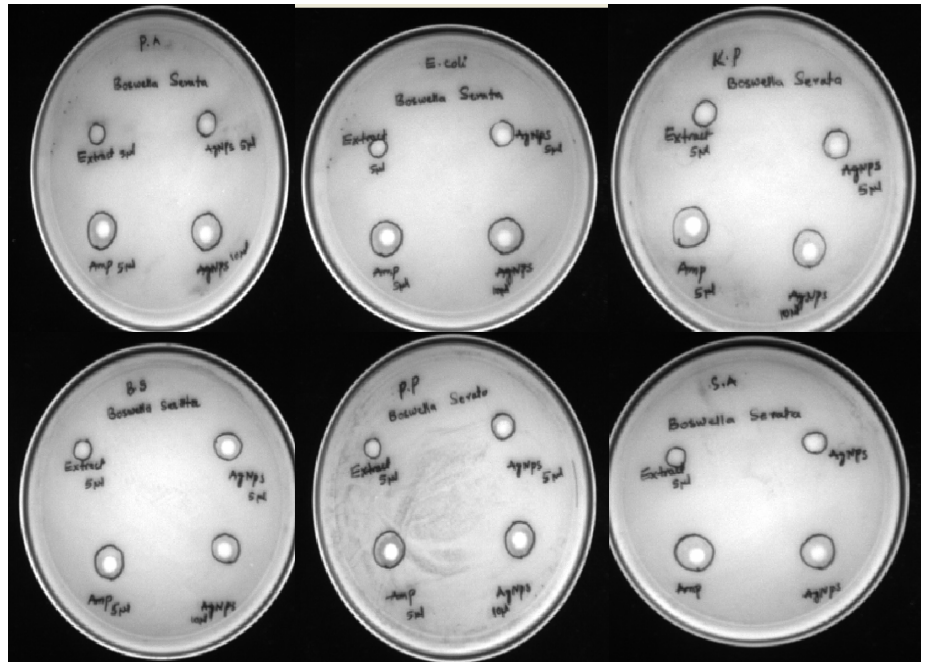

Figure 7: Antibacterial activity of the silver nanoparticles synthesized from Boswellia serrata flower against Gram Positive and Gram Negative 


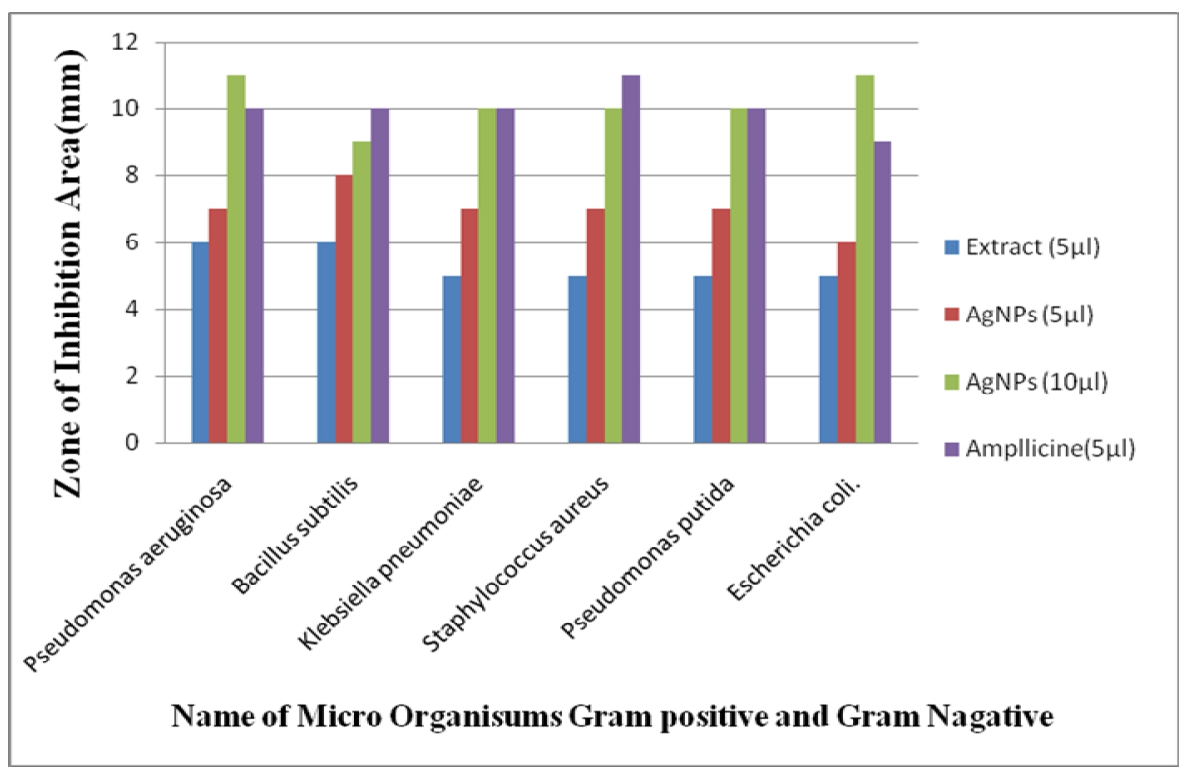

Figure 8: Antimicrobial activity of silver nanoparticles synthesized from Boswellia serrate flower extract

Strong absorption bands at 3350,2125, 1740, 1638, 1441, $1369,1213 \mathrm{~cm}-1$ are indicative of alkyne $\equiv \mathrm{C}-\mathrm{H}$, alcohols, phenols $(\mathrm{O}-\mathrm{H})$, carbonyl $\mathrm{C}=\mathrm{O}$, alkanes $(\mathrm{C}-\mathrm{H})$, alcohols, ethers, carboxylic acid ester $(\mathrm{C}-\mathrm{O})$, silver $\left(\mathrm{Ag}^{0}\right)$, alkyl halide $(\mathrm{C}-\mathrm{Br})$. SEM analysis of synthesized silver nanoparticles (AgNPs) morphology was characterized by scanning electron microscope (SEM). After the completion of reaction, the nanoparticles placed on carbon coated copper grid, exhibited spherical and rod shape (Figure 5). The size of the silver nanoparticle ranges around $60-84 \mathrm{~nm}$. Boswellia serrata flower extract reduced silver solutions were dried, drop coated on to carbon film. The EDAX pattern thus clearly shows that the silver nanoparticles are crystalline in nature by the reduction of silver ions by using flower broth. It shows strong signal in the silver region and confirms the formation of nanoparticles. Silver nanocrystals show typical optical absorption peak approximately at $20.00 \mathrm{keV}$ due to SPR. Other elemental $(\mathrm{O}, \mathrm{Cl}, \mathrm{C}, \mathrm{K}, \mathrm{Mg}, \mathrm{Na}, \mathrm{Ca}$ and $\mathrm{Si})$ signals are recorded possibly due to elements from enzymes or proteins present within the flower extract. The bioreduced silver nanoparticles drop coated onto glass substrates were done for the determination of the formation of silver by an X-ray diffract meter instrument (Figure 6) operated at a voltage of $20.00 \mathrm{kV}$. The inhibition zone was observed against Bacillus subtilus, Klebsiella planticola, Escherichia coli, Pseudomonas putida, staphylococcus aurous and Pseudomonas aeruginosa. Quantitative assay of the flower extract against bacteria's is shown in Figure 7. Bacteria's inhibition zone was compared to drug Ampicillin and the results are presented in (Figure 8 and Table 1). From standard values, it is evident that the synthesized nanoparticles are good candidates for usage as antibacterial drugs.

\section{ACKNOWLEDGEMENTS}

The authors acknowledge Director of CFRD-OU-Hyderabad, India for FTIR analysis and the authors are grateful to Coordinator, DBT-ISLARE, Osmania University, Hyderabad, India for providing necessary infrastructural facilities.

\section{REFERENCES}

1. Arangasamy Leela and Munusamy Vivekanandan. Tapping the unexploited plant resources for the synthesis of silver nanoparticles. African Journal of Biotechnology 2008; 7(17): 3162-3165.

2. M IP, SL Lui, VKM Poon, I Lung, A Burd. Antimicrobial activities of silver dressings: an in vitro comparison, J. Medical Microbiol 2006; 55: 59-63. http://dx.doi.org/10.1099/jmm.0.46124-0 PMid:16388031

3. SS Shankar, A Ahmad, R Pasricha, M Sastry. Bioreduction of chloroaurate ions by geranium leaves and its endophytic fungus yields gold nanoparticles of different shapes, J. Mater. Chem 2003; 13: 1822. http://dx.doi.org/10.1039/b303808b

4. SS Shankar, A Rai, A Ahmad, M Sastry. Rapid synthesis of Au, Ag and bimetallic Au core-Ag shell nanoparticles using Neem (Azadirachta indica) leaf broth J. Colloid. Interface. Sci 2004; 275: 496. http://dx.doi.org/10.1016/j.jcis.2004.03.003 PMid:15178278

5. Pal Sukdeb, Yu Kyung Tak and Joon Myong Song. Does the antibacterial activity of silver nanoparticles depend on the shape of the nanoparticle? A study of the gram-negative bacterium Escherichia coli. Applied and Environmental Microbiology, Appl. Environ. Microbiol 2007; 73(6): 1712. http://dx.doi.org/10.1128/AEM.02218-06

6. Karunakar Rao Kudle,Manisha R. Donda, Alwala Jahnavi, Koyyati Rama, Nagati Veerababu, Merugu Ramchander, Y Prashanthi, Rudra MP Pratap. Biofabrication of silver nanoparticles using Cuminum cyminum through microwave irradiation. International Journal of Nanomaterials and Biostructures 2012; 2(4): 65-69.

7. Karunakar Rao Kudle,Manisha R. Donda, Merugu Ramchander, Y Prashanthi, Rudra MP Pratap. Microwave assisted green synthesis of silver nanoparticles using Stigmaphyllon littorale leaves, their characterization and anti-microbial activity. International Journal of Nanomaterials and Biostructures 2013; 3(1): 13-16.

Cite this article as:

Karunakar Rao Kudle, Manisha R. Donda, Ramchander Merugu, Madhukar Rao Kudle, M.P. Pratap Rudra. Microwave assisted green synthesis of silver nanoparticles using Boswellia serrata flower extract and evaluation of their Antimicrobial activity. Int. Res. J. Pharm. 2013; 4(6):197-200 